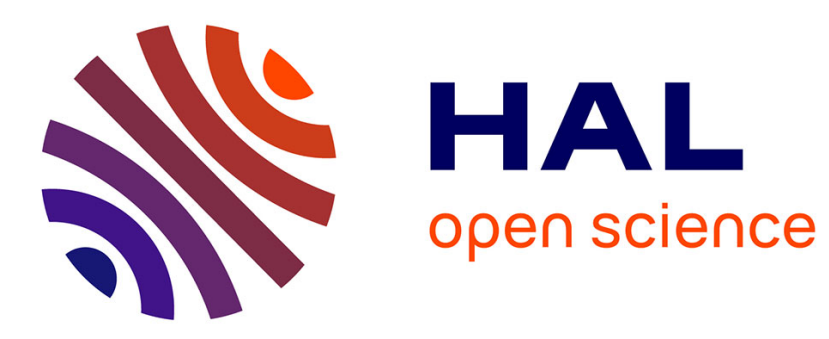

\title{
Surface modification of silica particles by dry coating: Characterization and powder ageing
}

Yamina Ouabbas, Alain Chamayou, Laurence Galet, Michel Baron, Gérard Thomas, Philippe Grosseau, Bernard Guilhot

\section{- To cite this version:}

Yamina Ouabbas, Alain Chamayou, Laurence Galet, Michel Baron, Gérard Thomas, et al.. Surface modification of silica particles by dry coating: Characterization and powder ageing. Powder Technology, 2009, 190 (1-2), pp.200-209. 10.1016/j.powtec.2008.04.092 . hal-00410918

\section{HAL Id: hal-00410918 \\ https://hal.science/hal-00410918}

Submitted on 25 Aug 2009

HAL is a multi-disciplinary open access archive for the deposit and dissemination of scientific research documents, whether they are published or not. The documents may come from teaching and research institutions in France or abroad, or from public or private research centers.
L'archive ouverte pluridisciplinaire HAL, est destinée au dépôt et à la diffusion de documents scientifiques de niveau recherche, publiés ou non, émanant des établissements d'enseignement et de recherche français ou étrangers, des laboratoires publics ou privés. 


\title{
Surface modification of silica particles by dry coating: Characterization and powder ageing
}

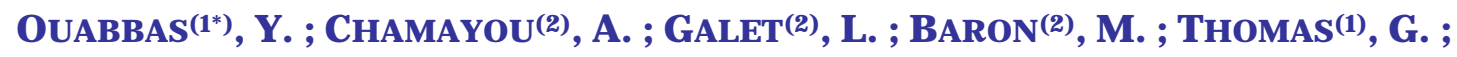 \\ GROSSEAU(1), P.; GUILHOT( $^{(3)}$, B.
}

(1) Département PMMC (Poudres et Matériaux Multi Composants), Centre SPIN. LPMG UMR CNRS 5148. Ecole Nationale Supérieure des Mines de Saint-Etienne 158, Cours Fauriel. 42023 Saint-Etienne Cedex 2.

(2) Ecole Nationale Supérieure des Techniques Industrielles et des Mines d'Albi-Carmaux, Centre RAPSODEE - UMR CNRS 2392, Campus Jarlard - 81013 Albi, France

(3) Centre CIS, LPMG UMR CNRS 5148. Ecole Nationale Supérieure des Mines de SaintEtienne 158, Cours Fauriel. 42023 Saint-Etienne Cedex 2.

(*) ouabbas@emse.fr

Keywords:

Dry coating; Hybridizer; Cyclomix; Flowability; Wettability; Powders ageing

\begin{abstract}
In this study the dry coating experiments were performed with two different processes using a high energy impact coater "Hybridizer" (Nara) and a high shear mixer "Cyclomix" (Hosokawa). Silica gel particles $\left(d_{50}=55 \mu \mathrm{m}\right)$ were coated with fine particles of magnesium stearate $\left(d_{50}=4.6 \mu \mathrm{m}\right)$ at two different weight ratio of magnesium stearate, $5 \%$ and $15 \%$. Several methods of characterization were used to study the effect of dry coating of the silica gel powder.

The uncoated and coated silica gel particles were observed by environmental scanning electron microscopy (ESEM). The images have shown that a more uniform coating was obtained in the case of Hybridizer. The flowability of the different samples obtained with Hybridizer and Cyclomix have been characterized by measurements of the tapped and aerated densities. It has been shown that the flowability of silica gel treated in Hybridizer was not significantly affected whereas the flowability was reduced after treatment in the Cyclomix. The wettability of silica gel was determined by measurements of the contact angle between a water drop and a powder bed prepared for each sample. The results obtained have shown that the coating of silica gel powder by hydrophobic magnesium stearate in the two different devices, Hybridizer and Cyclomix, can improve its hydrophobic properties. The results of the different characterizations have been compared with those concerning the simple mixtures prepared by using a Turbula mixer.
\end{abstract}

To investigate the stability and the ageing of silica gel particles after coating, three samples of silica gel coated with $15 \%(\mathrm{w} / \mathrm{w})$ of magnesium stearate in the Hybridizer device have been stored under different relative humidities (RH). The temporal evolution of the contact angle and the volume of the drop water on the surface of the bed powder have been determined after 10 days or 36 days storage. The results have shown the influence of the relative humidity on the evolution of the coated silica gel particles. The surface of the host particles recovers its hydrophilic nature after 10 or 36 days storage under different relative humidity. No significant variations of the contact angle and the volume of the drop were recorded for the sample stored under dry atmosphere $(\mathrm{RH}<12 \%)$. The ESEM observations of the different samples confirmed the results. A mechanism that can explain these ageing effects is proposed. 


\section{Introduction}

Dry particle coating to change the surface properties and/or functionality of powders appears as a very important process for many industries. Typical applications include modification of flowability, wettability (hydrophobic/hydrophilic properties), solubility, dispersibility, flavour, particle properties.

In dry particle coating processes, materials with relatively large particle size (host particles; $1-500 \mu \mathrm{m}$ ) are mechanically coated with fine particles (guest particles; $0.1-50 \mu \mathrm{m}$ ) in order to create new functionality or to improve their initial characteristics [1]. Since the size of the guest particles is so small, van der Waals interactions are strong enough to keep them firmly attached to the host particles. Thus, either a discrete or continuous coating of guest particles can be achieved depending on a variety of operating conditions including processing time, rotation speed, weight fraction of guest to host particles and particle properties [2]. Fig. 1 below illustrates the process of dry particle coating. Multiple layering is possible when using different coating materials and processing them one after other. Kangwantrakool et al. [3] have described a method to make multilayer coating of guest particles.

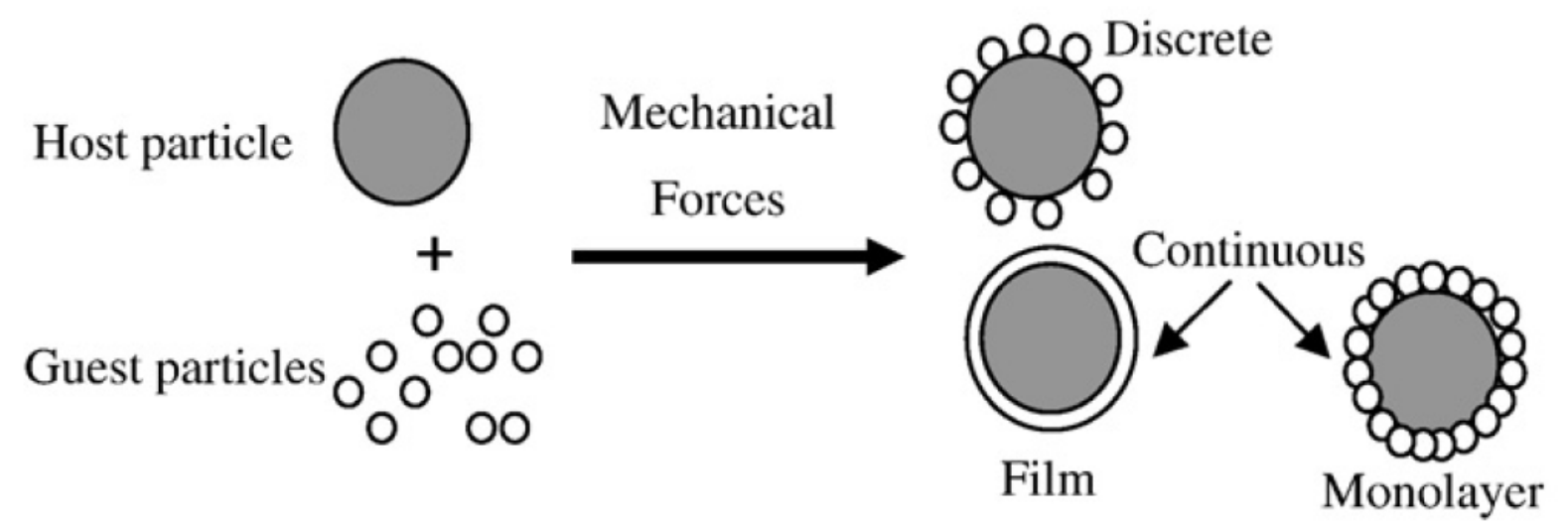

Fig 1: Dry particle coating principle.

The subject of dry coating is very closely related to the subject of dry mixing powders. In ordered mixing (a term coined by Hersey [4]), the surface of larger particles is loosely coated with smaller particles. In dry particle coating, the same thing happens; however, the surface covering is more permanent because of a stronger physical (or chemical) bonding [2]. Initial work on ordered mixing was done by Hersey and co-workers [4], [5], [6], [7], [8] and [9]. The concept of ordered mixing was also taken one step further (to dry coating) by using dry impact blending, as described in a series of papers by a Japanese group [10], [11], [12] and [13]. Several different dry coating machines have been developed allowing the creation of new types of materials. Pfeffer [2] gives descriptions of these different dry coating systems. Mujumbar et al. [14] have studied dry coating to enhance the moisture resistance of ground magnesium powder by coating its surface with carnauba wax. Yang et al. [15] showed that it is possible to improve the flowability of cornstarch by coating with nanosized silica.

The physical and physicochemical characterization of the powders and the interactions between host and guest particles play an important role in factors that affect the quality of the finished product, in particular the physical and chemical stability and the powder ageing. These characteristics are often dependent on the process and environmental conditions (humidity and temperature). During lifetime of powders, in particular food powders and pharmaceutical active substances, they will be subjected to a wide range of temperatures and 
relative humidities associated with handling, conditioning, storage and transport. These factors can significantly affect the stability and the ageing of different powders. It is extremely important and difficult to preserve the quality of products because they are susceptible to various changes such as moisture uptake.

In this paper we describe an experimental investigation of an application of dry coating technique to study the effect of mechanical dry coating on the flowability and the wettability of silica gel particles coated with two different weight ratio of magnesium stearate by using a high energy impact blending coater "Nara Hybridizer" and a high shear mixer "Cyclomix".

To provide explanations on how the stability and the quality of the coated particles change with time under the influence of the storage conditions, in particular relative humidity, three samples of silica gel particles coated in the Hybridizer with $15 \%(\mathrm{w} / \mathrm{w})$ of magnesium stearate have been stored under different conditions at room temperature $\left(20 \pm 2{ }^{\circ} \mathrm{C}\right)$ : at ambient relative humidity $(45 \% \pm 10 \%)$, in a desiccator at relatively dry atmosphere $(\mathrm{RH}<12 \%)$ or under constant relative humidity $(\mathrm{RH}=33 \% \pm 1 \%)$. The moisture treatments were made in a desiccator containing saturated $\mathrm{MgCl}_{2}$ salt solution at room temperature, thus giving a relative humidity in the desiccator of approximately 30\%. The temporal evolution of the contact angle and the volume of the drop water on the surface of the bed powder have been determined after 10 days or 36 days storage.

\section{Experimental}

\section{Powders}

Silica gel powder supplied by Merck and usually used for the filling of columns of chromatography has been chosen as host particles for dry coating. The silica gel is sensitive to the variations of humidity because of its porous structure. As shown in Fig. 2(A), the environmental scanning electron microscope (ESEM) image indicates that the silica gel particles are irregularly shaped and the surface is rough.

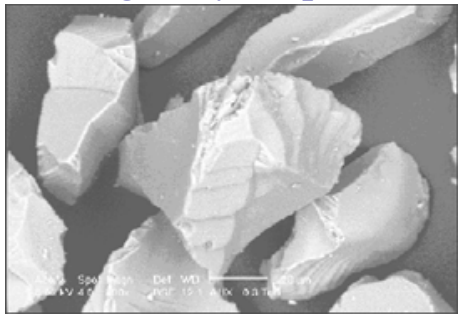

(a)

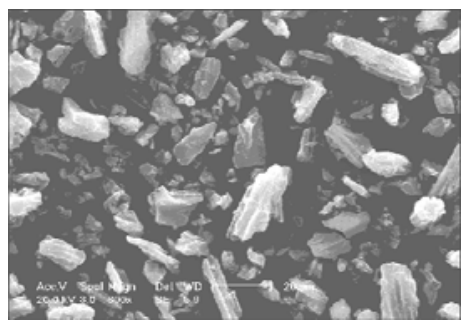

(b)

Fig 2: ESEM images of host and guest particles. (a) Silica gel; (b) MgSt

Hydrophobic magnesium stearate (MgSt) supplied by Chimiray is used as guest particles. The MgSt is a fine, white, greasy and cohesive powder widely used in pharmaceutical formulation as a lubricant. An ESEM image for MgSt (Fig. 2(B)) shows different particle shapes including the needle and plate configurations.

Fig. 3 shows the particle size distributions of silica gel and MgSt obtained with a Malvern dry feed system (Mastersizer 2000). The volume distribution of silica gel shows a population of large particles with median diameter $\left(d_{50}\right)$ of about $50 \mu \mathrm{m}$. However, a wider size distribution is observed for MgSt particles. The size of MgSt particles varies between $20 \mu \mathrm{m}$ to less than $1 \mu \mathrm{m}$ with a median diameter $\left(d_{50}\right)$ of about $5 \mu \mathrm{m}$. The main properties of host and guest particles used in the experiments are summarized in Table 1. 
Table 1: Properties of host and guest particles

\begin{tabular}{c|ccc} 
Particles & $\begin{array}{c}\text { Size }\left(\mathrm{d}_{50}\right)(\mu \mathrm{m}) \\
(\text { Mastersizer 2000) }\end{array}$ & $\begin{array}{c}\text { True density }(\rho)\left(\mathrm{g} / \mathrm{cm}^{3}\right) \\
\text { (Helium Pycnometer) }\end{array}$ & $\begin{array}{c}\text { Specific surface area (SBET) }\left(\mathrm{m}^{2} / \mathrm{g}\right) \\
\text { (Micromeritics ASAP 2010) }\end{array}$ \\
\hline $\begin{array}{c}\text { Silica } \\
\text { gel }\end{array}$ & $55\left(D_{\text {host }}\right)$ & $2,07\left(\rho_{\text {host }}\right)$ & 475 \\
$\mathrm{MgSt}$ & $4,6\left(d_{\text {guest }}\right)$ & $1,04\left(\rho_{\text {guest }}\right)$ & 7.7
\end{tabular}
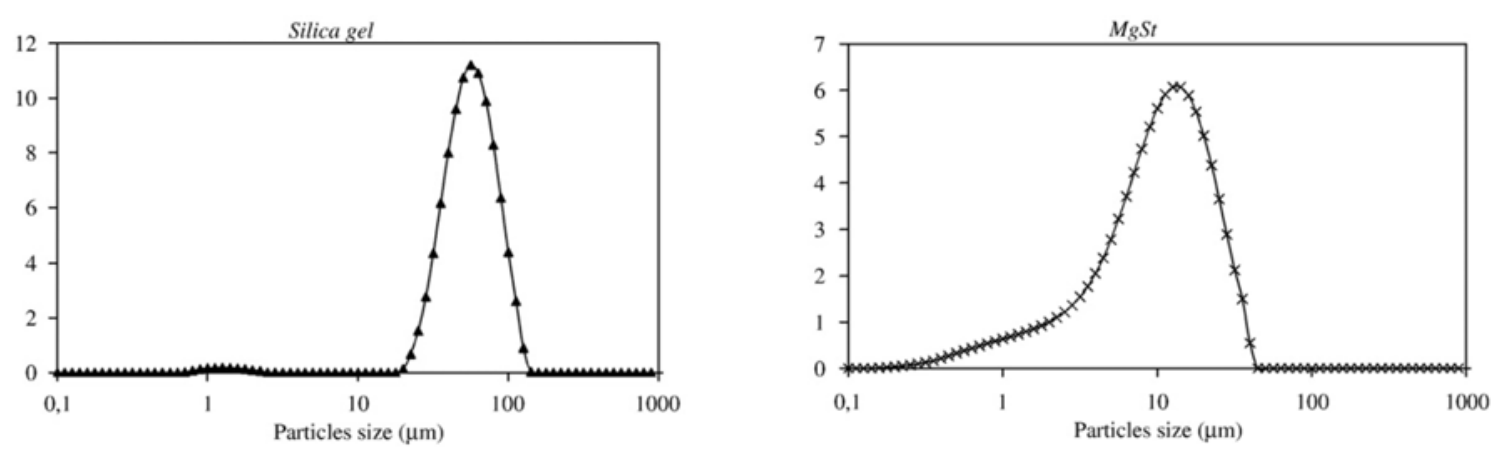

Fig 3: Particle size distributions of host (silica gel) and guest particles (MgSt).

\section{Coating processes}

The evolution of the percentage by mass of guest particles used in coating experiment is calculated based on the assumption of $100 \%$ surface coverage of the host particles with a monolayer of guest particles. We assume that all guest particles are of same size, both host and guest particles are spherical, and that the shapes of host and guest particles do not change during the coating process. Based on these assumptions, the mass percentage $(W)$ of guest particles for $100 \%$ coverage can be written as [15]:

$W(\%)=\frac{\left(N d_{\text {guest }}^{3} \rho_{\text {guest }}\right)}{\left(D_{\text {host }}^{3} \rho_{\text {host }}\right)+\left(N d_{\text {guest }}^{3} \rho_{\text {guest }}\right)} \times 100$

For $D_{\text {host }} \gg D_{\text {guest }}$ (here $\frac{D_{\text {host }}}{D_{\text {guest }}} \approx 10$ ), the number $N$ of guest particles per host particle is given by the expression:

$N=\frac{4\left(D_{\text {host }}+d_{\text {guest }}\right)^{2}}{d_{\text {guest }}^{2}} \times 100$

From Eq. (1), the percentage of guest particles needed to coat is $15 \%$. In addition, coating experiments have been carried out with $5 \%$ of magnesium stearate.

Two different dry coating devices were studied to determine the coating performance as described below: Hybridization system (NHS-O; Nara Machinery Co.) is a high-speed dry impact blending coater, which comprises an OM. Dizer, the hybridizer, the product collector and the control panel [1] and [16]. Fig. 4 is a schematic diagram of the hybridizer. It consists of a high-speed rotating rotor with six blades, a stator and a powder re-circulation circuit [14]. The coating chamber is surrounded with a jacket in which coolant is circulated [3]. The processing can be summarized as follows: the powder mixture (host and guest particles) is subjected to high impaction and dispersion due to collisions with blades and the walls of the device and continuously re-circulates in the machine through the cycle tube. Particle coating 
is achieved due to the embedding or filming of the guest particles onto the host particles by high impaction forces and friction heat [15]. Since the rotor of the hybridizer can rotate anywhere from 5000 to $16,000 \mathrm{rpm}$, very short processing time is required to achieve coating [2]. The operating conditions used in experiments were 4800 rpm for $5 \mathrm{~min}$.

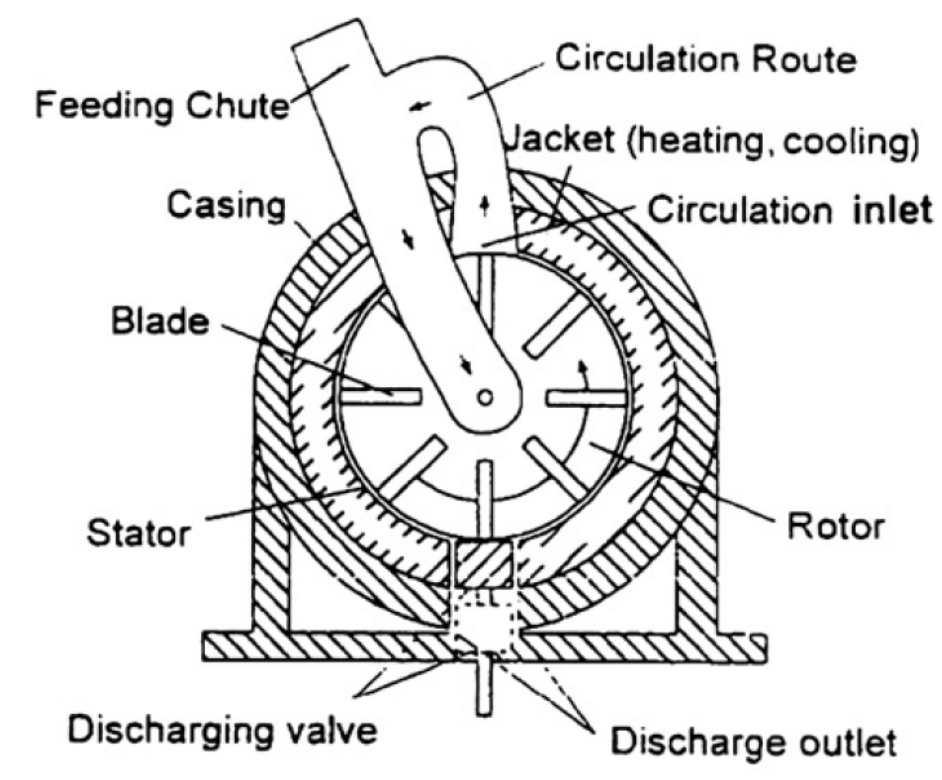

Fig 4: Design of the hybridizer apparatus [3]

Cyclomix (Hosokawa Micron B.V.) is a model of vertical high shear mixer granulator, provided by Hosokawa Micron, and has a nominal volume capacity of $1 \mathrm{~L}$. The mixer has four pairs of fat-bladed impellers from the bottom to the top. A centrally located high-speed rotating shaft is driven from the mixer cover, thus eliminating seals and bearings from the product zone. The shaft is fitted with paddle-shaped mixing elements, which rotate close to the inner vessel wall [18]. Fig. 5 is a schematic diagram of the Cyclomix mixer.

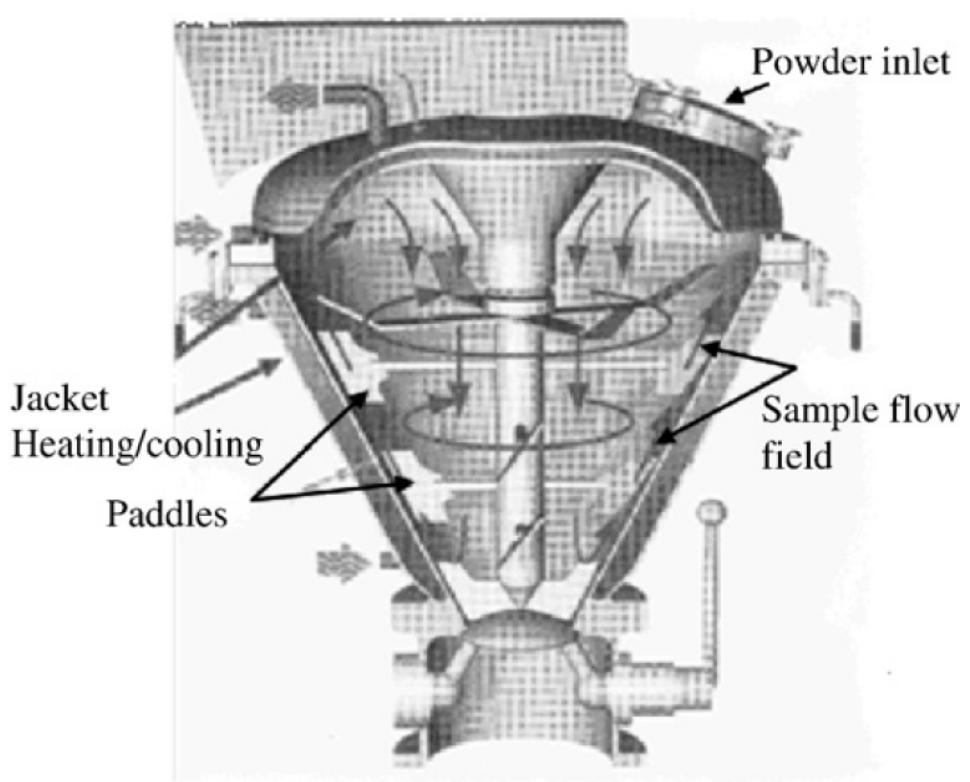

Fig 5: The Cyclomix high shear mixer [17]

The working principle of the Cyclomix differs markedly from the existing mixing techniques owing to the specific interaction between mixing element and vessel wall. The powder (host 
and guest particles) is loaded into the conical mixing vessel from the top; the degree of filling can range between 30 and $100 \%$. Together, the high-speed rotation (up to $3000 \mathrm{rpm}$ ) of the paddles and the conical shape of the vessel force the product from the bottom to the upper zone of the vessel. Upon reaching the top, the product flows downwards into the centre of the vessel. This flow pattern results in fast macromixing. During the upward motion, the particles are accelerated by the paddles and intensively mixed by friction with vessel walls. The operating conditions used in experiments are 1500 rpm for $5 \mathrm{~min}$.

\section{Characterization}

The uncoated and coated silica gel particles were examined by means of an environmental scanning electron microscopy (ESEM) to study the surface morphology and particle shapes before and after coating. The tapped density tester (ERWEKA Volumeter) has been used to examine the flowability of the uncoated and coated samples. The tapped density $\left(\rho_{\infty}\right)$ is obtained by mechanically tapping a powder sample contained in a $25 \mathrm{~mL}$ measuring cylinder. After having just poured the powder gently into the cylinder, the initial volume is read to determine the aerated density $\left(\rho_{\mathrm{o}}\right)$. The cylinder is mechanically tapped, and volume readings are taken until little volume change is observed. The flow properties of the uncoated and coated powders were evaluated by the Carr's flowability index (IC) and Hausner's ratio (HR).

Carr index $I C=\frac{\rho_{\infty}-\rho_{0}}{\rho_{\infty}} \%$

Haussner ratio $H R=\frac{\rho_{\infty}}{\rho_{0}}$

The wettability has been studied by the sessile drop method [19] and [20]. A small water drop of $10 \mu \mathrm{l}$ is deposited on the surface of a powder bed prepared for each sample. The shape of the drop profile is observed and used to determine the contact angle.

\section{Results and discussion}

\section{Surface morphology}

As shown on Fig. 2(A), the particle of silica gel in its original form is irregularly shaped. The shape of particles was not changed by the hybridizer treatment (Fig. 6(A)) but after processing in the Cyclomix, the silica gel particles were crushed, probably because of high shearing in the mixer (Fig. 6(B)).

The surface morphology of particles coated with $5 \%$ and $15 \%(\mathrm{w} / \mathrm{w})$ of $\mathrm{MgSt}$ in the Hybridizer and the Cyclomix compared to particles treated in Turbula is shown in Fig. 7. The ESEM images were carried out just after treatment because ageing of the coated silica gel powder ageing was observed in fewer 10 days.

The guest particles were discreetly distributed on the surface of silica gel particles after treatment with 5\% and 15\% (w/w) of MgSt in both the Hybridizer and the Cyclomix and also in the Turbula mixer (Fig. 7). Greater MgSt coverage is observed on the surface of silica gel as the MgSt percentage is increased to $15 \%(\mathrm{w} / \mathrm{w})$. Much more free fine particles were observed in the product from Turbula mixer. 


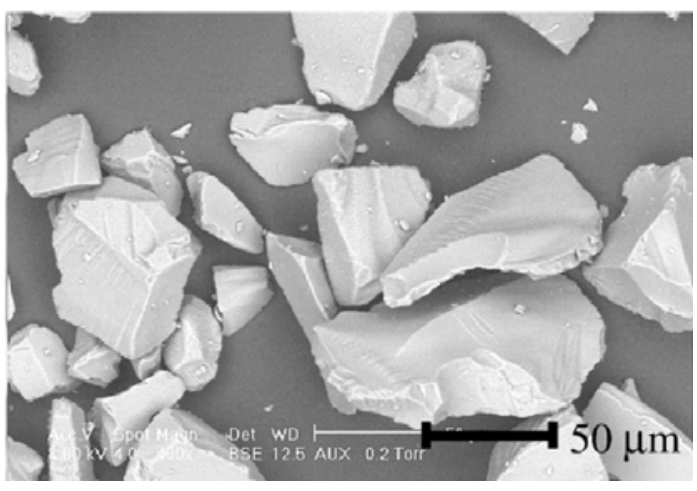

(A)

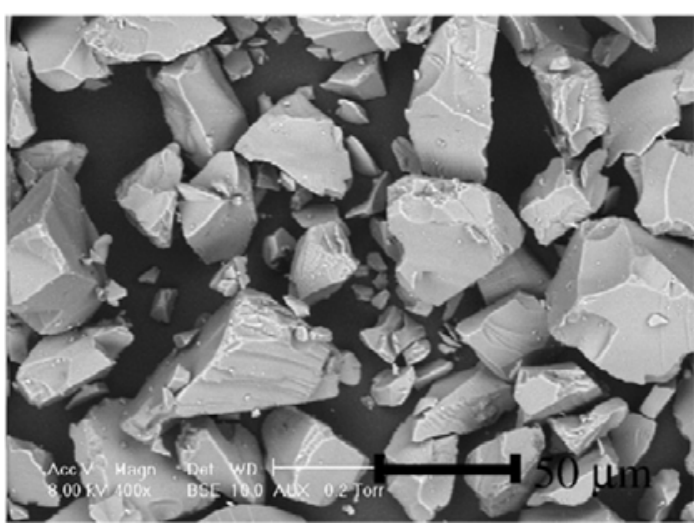

(B)

Fig 6: ESEM images of Silica gel particles treated alone: (A) in Hybridizer and (B) in Cyclomix.

As shown in Fig. 8, the surface coverage with 15\% of MgSt seems to be more uniform and the MgSt is much more softened and smeared over the surface of silica gel particles processed in the Hybridizer. After treatment in the Turbula mixer, the surface coverage is less uniform than for particles processed in both the Hybridizer and the Cyclomix.

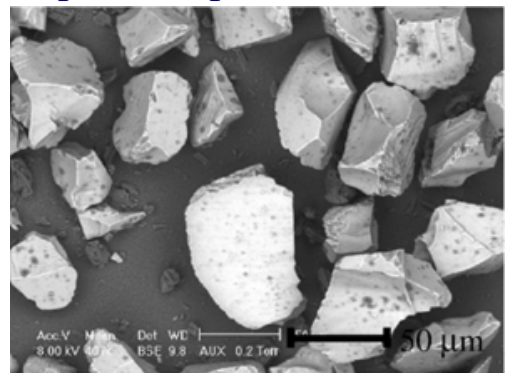

(A)

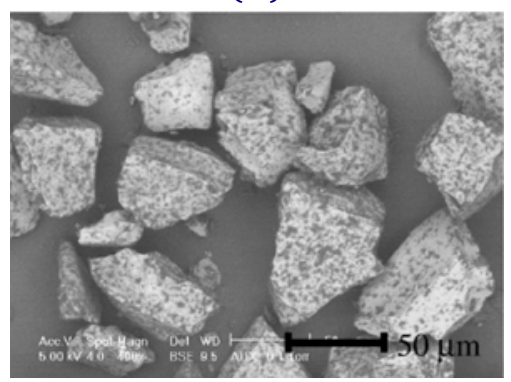

(B)

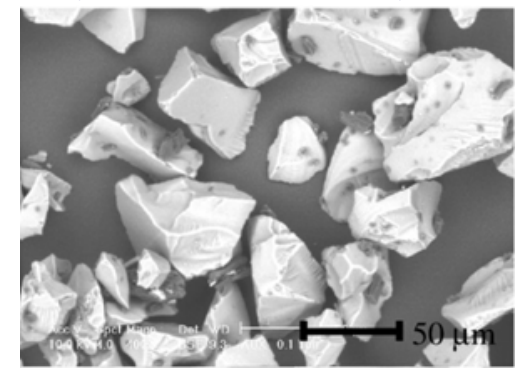

(C)

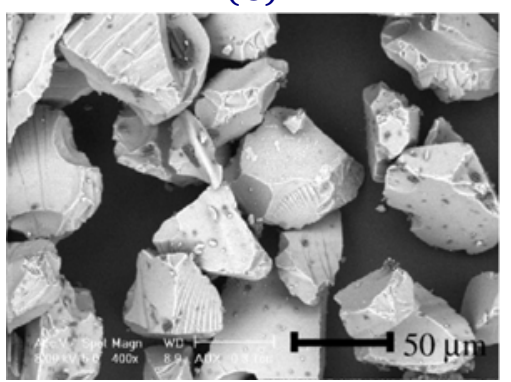

(D)

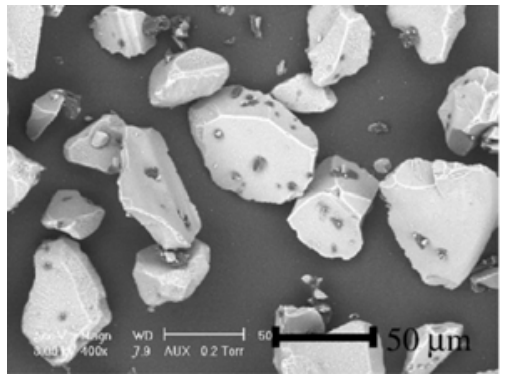

(E)

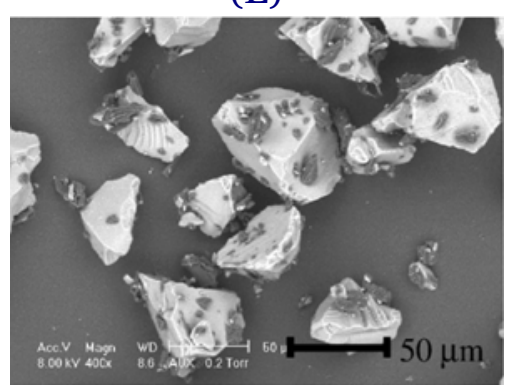

(F)

Fig 7: ESEM images of Silica gel particles treated with 5\% (w/w) of MgSt: $(A)$ in Hybridizer; $(C)$ in Cyclomix and (E) in Turbula. Treated with 15\% (w/w) of MgSt: (B) in Hybridizer; (D) in Cyclomix and $(F)$ in Turbula.

Flowability tests

The values of the Carr's flowability index (IC) and Hausner's ratio (HR) of uncoated and coated silica gel particles and MgSt are summarized in Table 2. The as-received silica gel powder presents good flow properties ( $I C=15.22$; $H R=1.18$ ). After processing in the Hybridizer, the flowability of silica gel is not affected and remains good enough whereas the treatment in the Cyclomix reduces the flow properties because of the grinding of particles as shown on Fig. 9 which represents the variation of the density measured for the as-received silica gel, silica gel processed alone in both the Hybridizer and the Cyclomix and MgSt. 


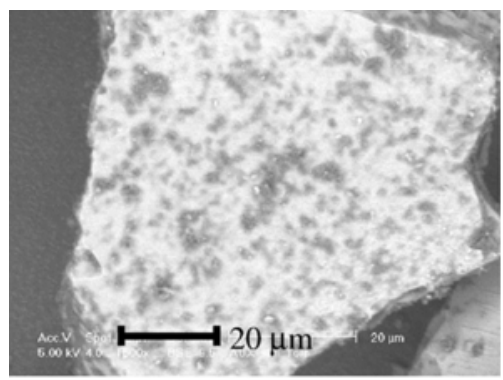

$15 \%$ MgSt-Hybridrizer

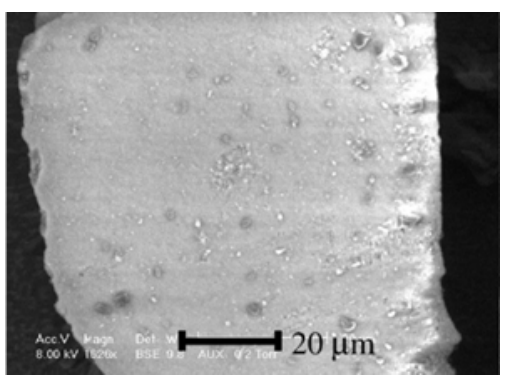

$15 \%$ MgSt-Cyclomix

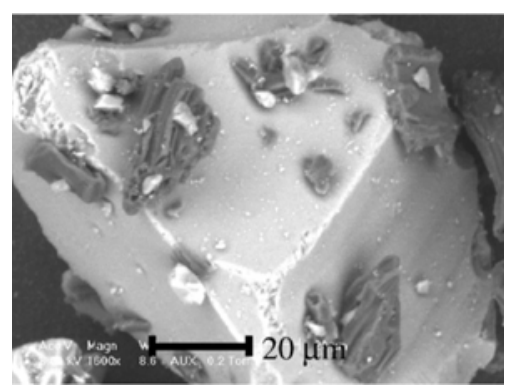

$15 \%$ MgSt-Turbula

Fig 8: ESEM images of the surface of Silica gel particle treated with 15\% (w/w) of MgSt in Hybridizer; Cyclomix and Turbula, showing the dispersion of MgSt on the silica gel surface.

The fine particles of MgSt have the lower flow properties because of the high cohesivity of this powder ( $\mathrm{IC}=34.10$; $\mathrm{HR}=1.52$ ). The tapped density is reached after 500 strokes for $\mathrm{MgSt}$ instead of 50 strokes for silica gel.

Table 2: The values of Carr's flowability index (IC) and Hausner's ratio (HR)

\begin{tabular}{|c|ccc|}
\hline Samples & IC & HR & Flowability \\
\hline As-received Silica gel & 15.22 & 1.18 & Good \\
\hline Silica gel_Hybridizer & 15.24 & 1.18 & Good \\
\hline Silica gel_Cyclomix & 18.45 & 1.23 & Mediocre \\
\hline 5\%MgSt_Hybridizer & 17.60 & 1.22 & Good \\
\hline 5\%MgSt_Cyclomix & 20.96 & 1.27 & Mediocre \\
\hline 5\%MgSt_Turbula & 26.30 & 1.40 & Bad \\
\hline 15\%Mgt_Hybridizer & 18.22 & 1.22 & Bediocre \\
\hline 15\%MgSt_Cyclomix & 21.21 & 1.27 & Bad \\
\hline 15\%MgSt_Turbula & 28.30 & 1.40 & Bad \\
\hline MgSt & 34.10 & 1.52 & \\
\hline
\end{tabular}

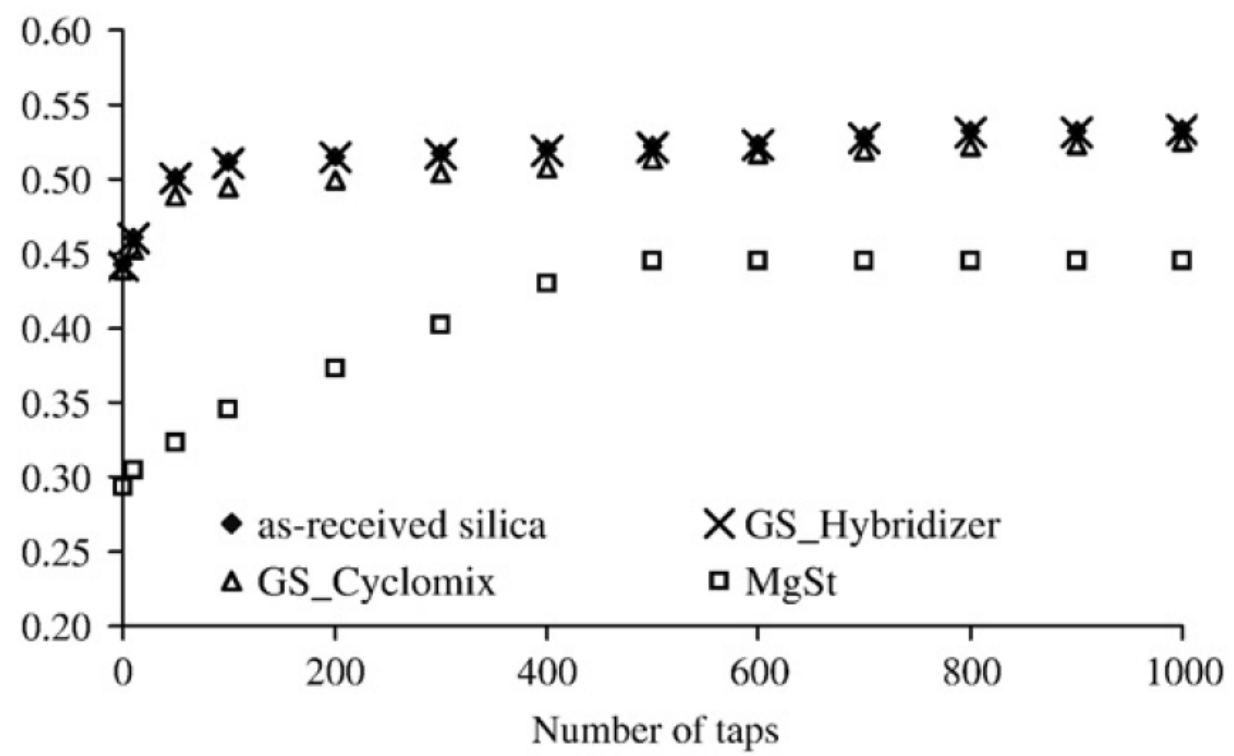

Fig 9: Flowability of silica gel particles before and after processing in the Hybridizer and the Cyclomix compared to the flowability of MgSt.

Fig. 10 shows the variation of the density measured for the silica coated with $5 \%$ and $15 \%$ of MgSt in both the Hybridizer and the Cyclomix. The results are compared to those obtained for silica gel particles treated in the Turbula mixer with $5 \%$ and $15 \%$ of MgSt. One can observe 
that for the particles treated in Hybridizer, the flow properties remain good for the coated particles with $5 \%$ of $\mathrm{MgSt}$ and decreases slightly for the weight percentage of $15 \%$ of MgSt. Due to the breakage of silica gel particles in the Cyclomix, the flowability becomes mediocre after coating with $5 \%$ of MgSt and decreases with $15 \%$ of MgSt. The flow indices (IC, HR) show that the flow properties of silica gel powder decrease significantly after treatment in the Turbula mixer (Table 2).
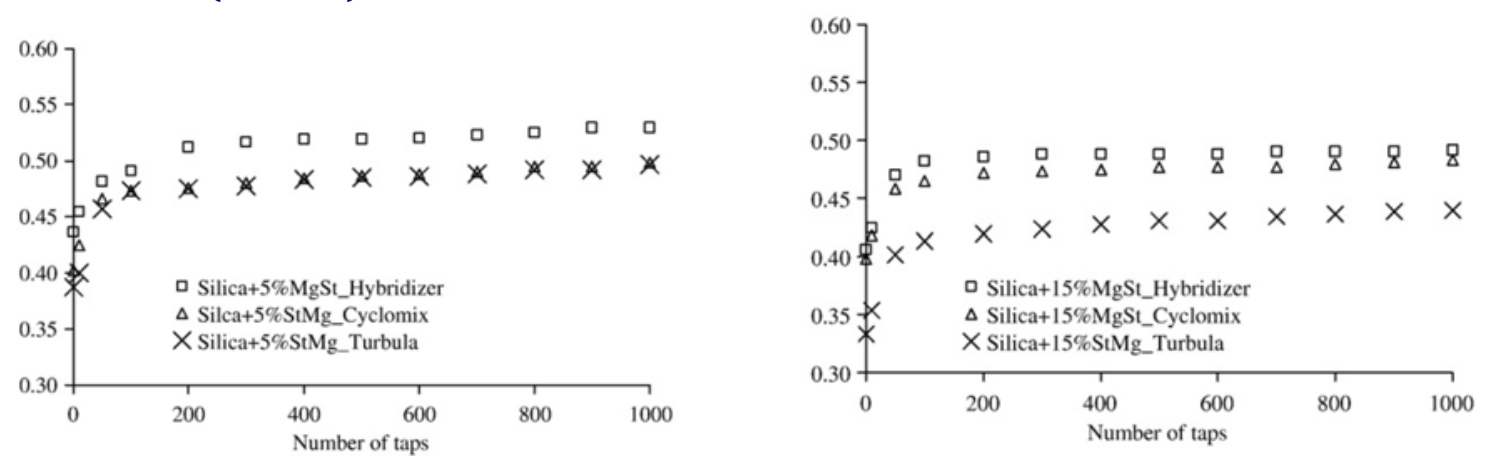

Fig 10: Flowability of coated host particles with different devices with 5\% and 15\% of MgSt.

\section{Wettability tests}

Since the MgSt is hydrophobic, the coating should make the hydrophilic silica gel surface become hydrophobic. To evaluate the impact of coating on the reduction of the high affinity between silica gel and water, wettability tests were carried out for the uncoated particles and the coated silica gel particles in both the Hybridizer and Cyclomix. The results are compared to those obtained for silica gel particles treated in the Turbula mixer with $5 \%$ and $15 \%$ of MgSt. Fig. 11 shows photos taken after two different times of contact between the water drop and the uncoated silica gel powder bed. It can be seen that the water drop disappears instantaneously (after $1 \mathrm{~s}$ ) from the surface because of the high affinity between silica gel and water.
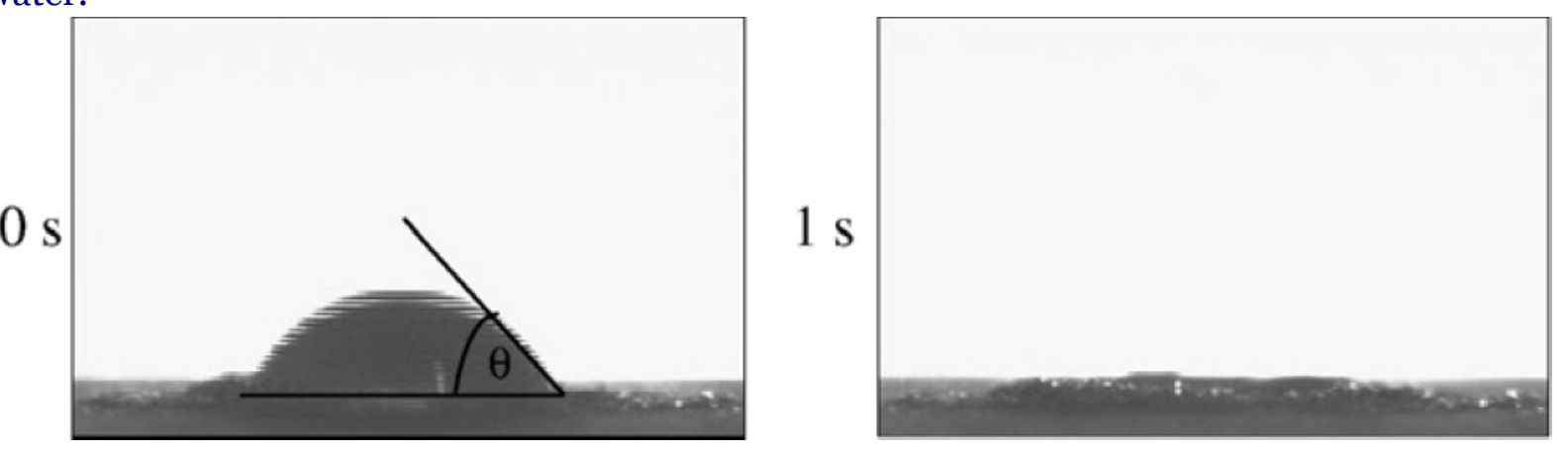

Fig 11: Wettability of silica gel powder before coating

After coating with 5 and $15 \%$ of MgSt in the Hybridizer (Fig. 12), the water drop is not absorbed and remains on the surface of silica gel powder. The same observations were noted after treatment with $5 \%$ and $15 \%$ of MgSt in the Cyclomix and the Turbula mixer. These results clearly prove on the one hand that the surface of the silica gel particles is coated by the MgSt particles and on the other hand that the affinity of the silica gel powder with water is reduced by dry coating in both the Hybridizer and Cyclomix. One has previously observed that the surface coverage with MgSt obtained after treatment in the Turbula mixer is the least uniform but the wettability measurements lead to the same results as for the Hybridizer and the Cyclomix. 

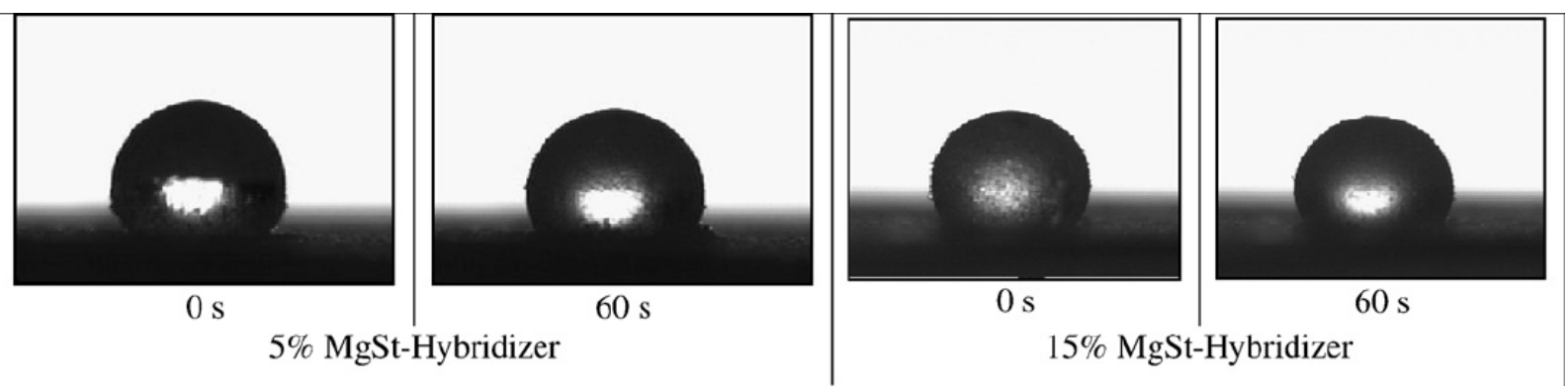

Fig 12: Wettability of coated silica gel particles with 5\% and 15\% of MgSt in the Hybridizer.

Powders ageing study

Sample analysis after 10 days storage

Fig. 13 shows the temporal variations of the contact angle and the volume of the water drop measured just after treatment in hybridizer with $15 \%$ of $\mathrm{MgSt}(t=0)$ and after a 10 days storage ( $t=10$ days) under different relative humidity conditions. One can observe that the contact angle and the volume of the water drop are practically constant after the first analysis of the sample $(t=0)$. As shown on Fig. 12, the water drop remains on the surface of the coated silica gel powder. After 10 days storage ( $t=10$ days), the contact angle and the volume of the water drop of the sample stored at ambient relative humidity $(\mathrm{HR}=45 \%)$ decrease (Fig. 13) until total absorption of the water drop on the surface of the powder bed after only $4 \mathrm{~s}$. This observation is illustrated by the photos taken at o $\mathrm{s}$ and $4 \mathrm{~s}$ of the water drop shown on Fig. 14 .
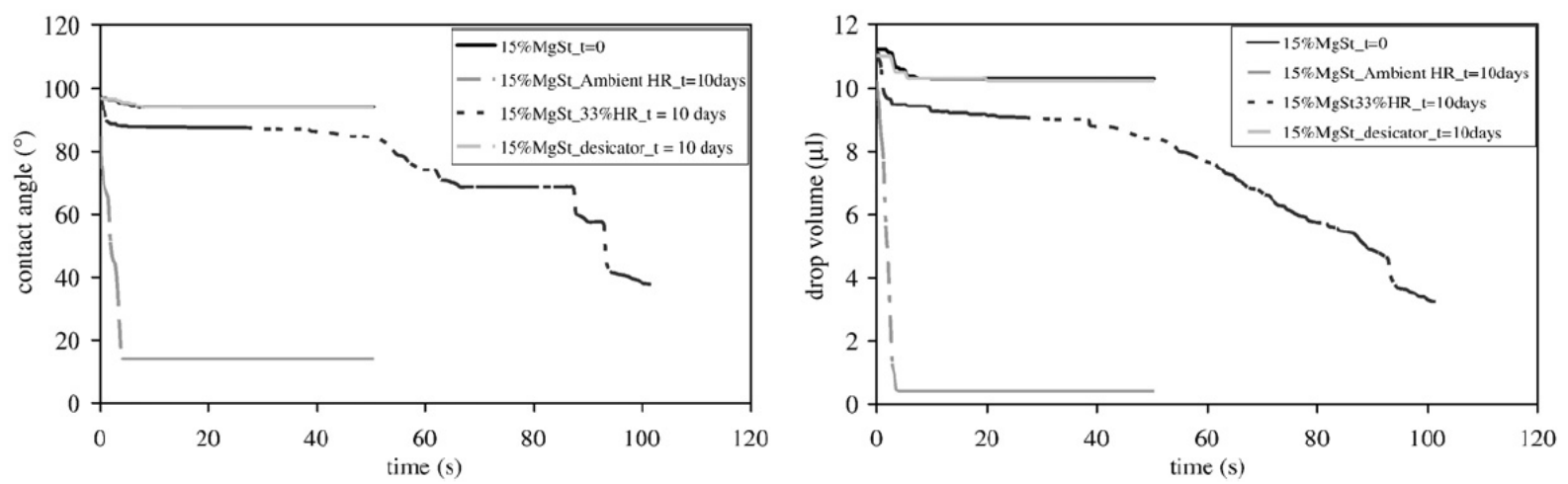

Fig 13: Temporal evolution of the contact angle and the volume of the water drop after 1o days storage.
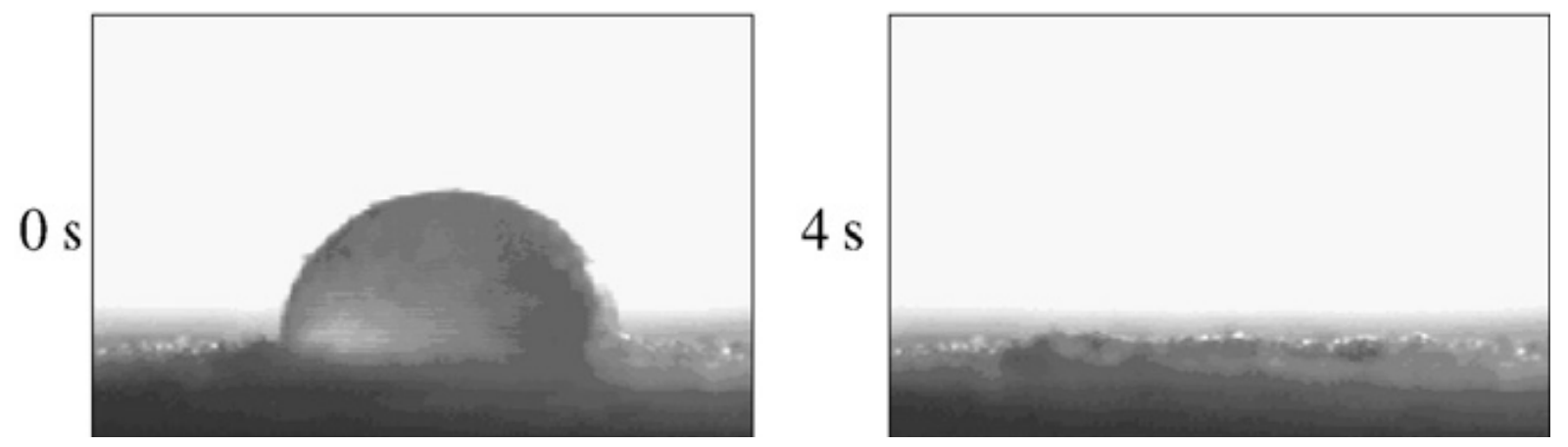

Fig 14: Evolution of the water drop after 10 days storage at ambient relative humidity.

For the sample stored under constant relative humidity of 33\%, the temporal variations of the contact angle and the volume of the water drop are slower (Fig. 13). The water drop is gradually absorbed on the surface of the powder bed (Fig. 15). 

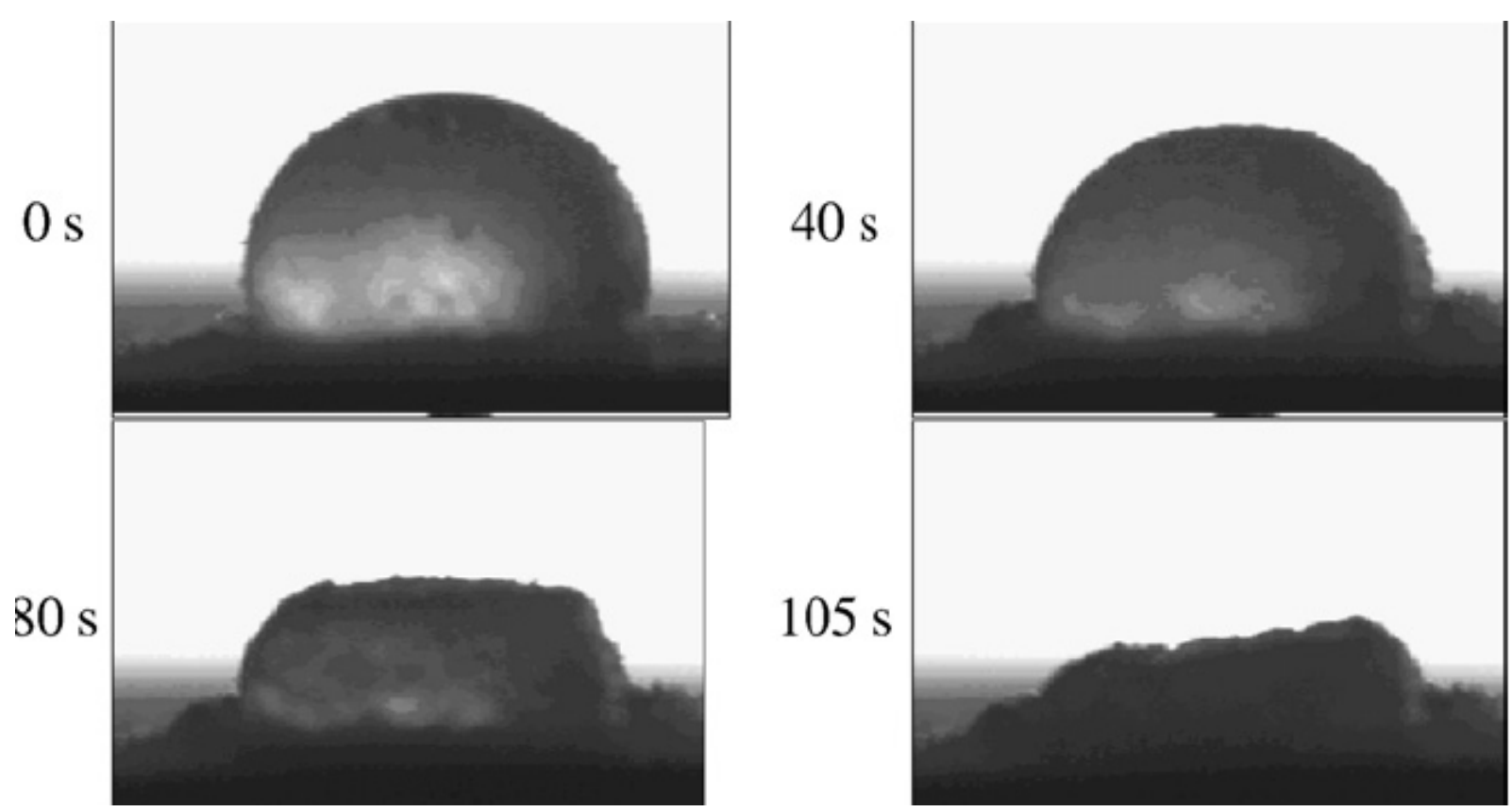

Fig 15: Evolution of the water drop after 10 days storage under constant $R H$ of 33\%.

Fig. 13 shows that the curves of the temporal variation of the contact angle and the volume of the water drop for the sample stored $\mathrm{RH}<12 \%$ are quite similar to those obtained just after treatment in Hybridizer $(t=0)$. As shown on Fig. 16, the water drop remains on the surface of the powder bed and the sample stored at this RH does not undergo any evolution after 10 days storage.
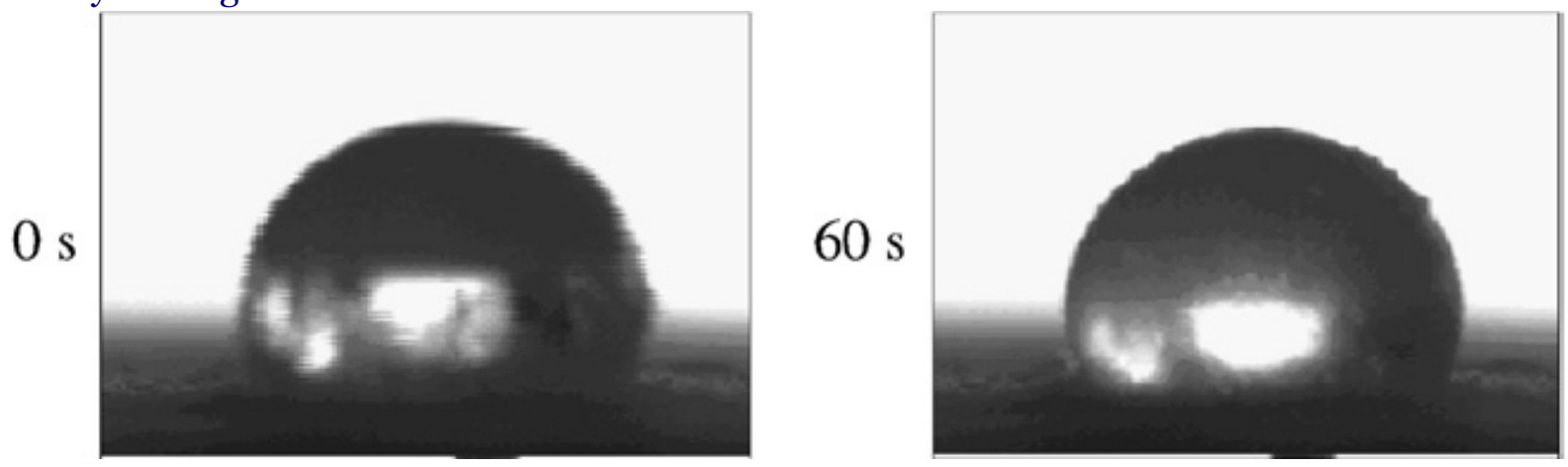

Fig 16: Evolution of the water drop after 10 days storage in a desiccator $(R H<12 \%)$.

The ESEM observations (Fig. 17) show that after 10 days storage, the surface areas of silica gel initially $(t=0)$ coated with MgSt by a treatment in the Hybridizer decrease for sample stored at ambient relative humidity $(\mathrm{RH}=45 \%)$ or under constant relative humidity of $33 \%$. The MgSt disappears gradually from the surface of silica gel particles. The decrease of the coating surface areas is more important for the sample stored at ambient relative humidity. For the sample stored in a desiccator under relatively dry atmosphere $(\mathrm{HR}<12 \%)$, the silica gel particles remain coated by MgSt. 


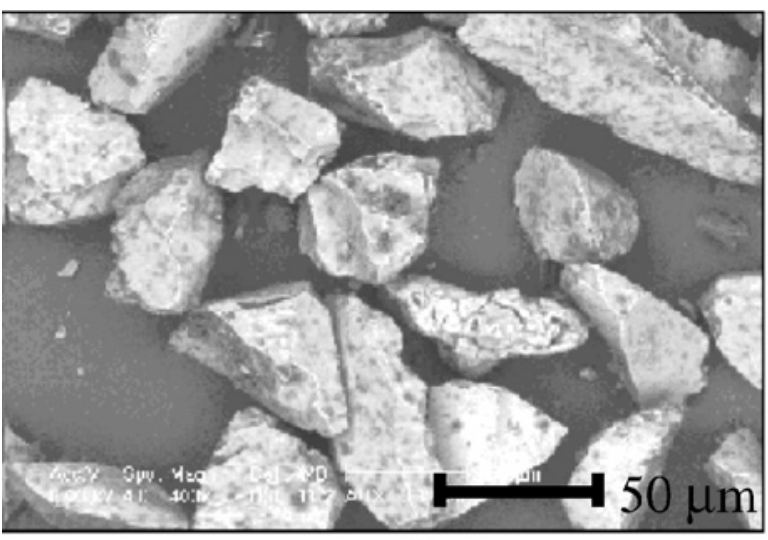

$\mathrm{t}=0$

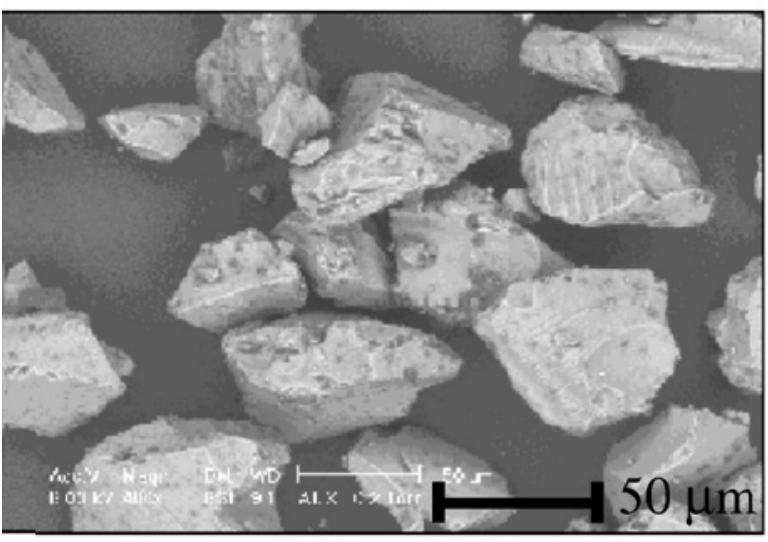

$\mathrm{RH}=33 \%$

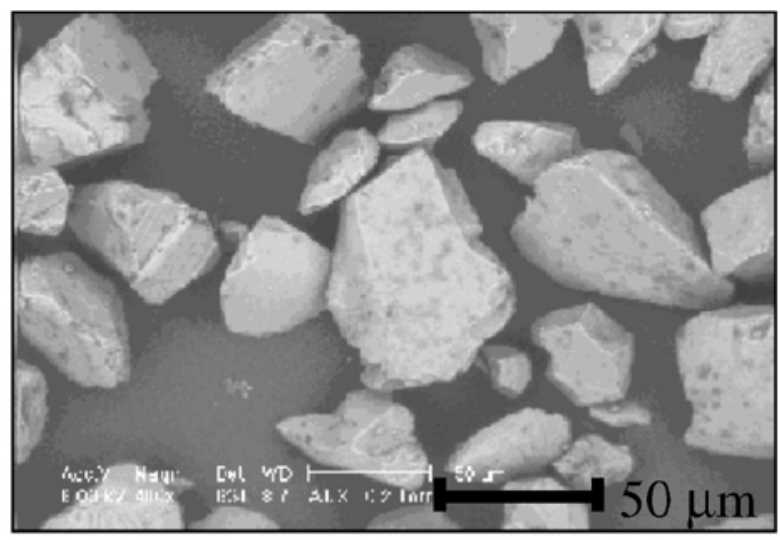

$\mathrm{RH}=45 \%$

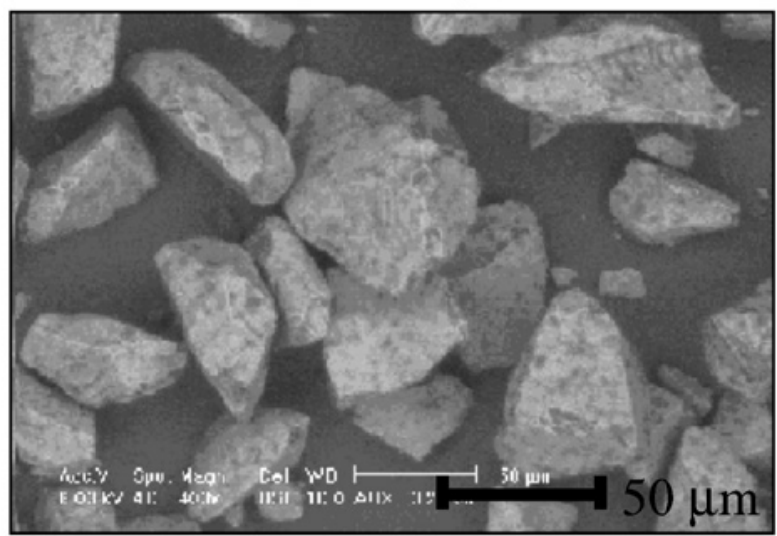

$\mathrm{RH}<12 \%$

Fig 17: ESEM images of silica gel particles coated with 15\% of MgSt at $\mathrm{t}=\mathrm{O}$ and after 10 days storage under three different relative humidity.

\section{Sample analysis after 36 days storage}

Samples analysed after 36 days storage ( $t=36$ days) shows a faster decrease of the contact angle and the volume of the water drop for the sample stored under constant RH (33\%) but especially for the sample stored at $\mathrm{RH}=45 \%$ (Fig. 18). The temporal evolutions of the contact angle and the volume of the water drop for the sample stored in a desiccator remain constant and similar to the results obtained after 10 days storage.
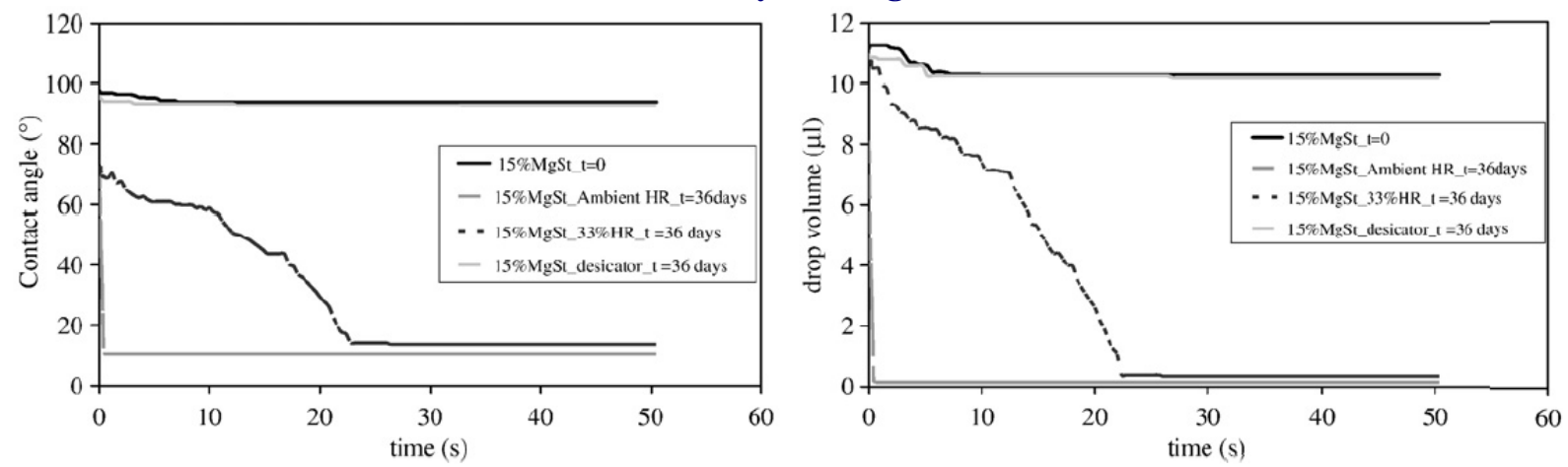

Fig 18: Temporal evolution of the contact angle and the volume of the water drop water drop after 36 days storage.

As shown on Fig. 19, after 36 days storage, the behaviour of the water drop on the surface of the powder bed prepared for the sample stored at $\mathrm{RH}=45 \%$ is the same one as the behaviour 
of the silica gel powder before coating with MgSt. The water drop disappears instantaneously (after $1 \mathrm{~s}$ ) on the surface of powder bed.

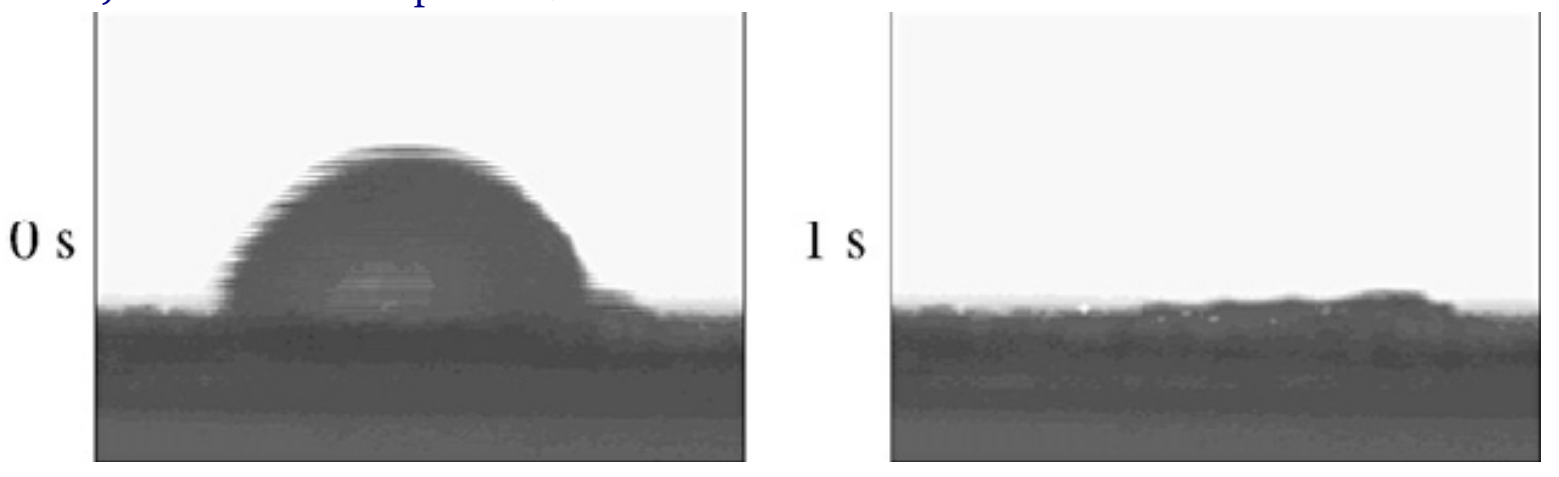

Fig 19: Evolution of the water drop after 36 days storage at ambient relative humidity (45\% $R H \pm 10 \%)$.

For the sample stored under constant relative humidity of $33 \%$, the water drop is gradually absorbed from the surface of the powder bed after 36 days storage (Fig. 20) The adsorption is more rapid after 36 days storage, than 10 days storage.
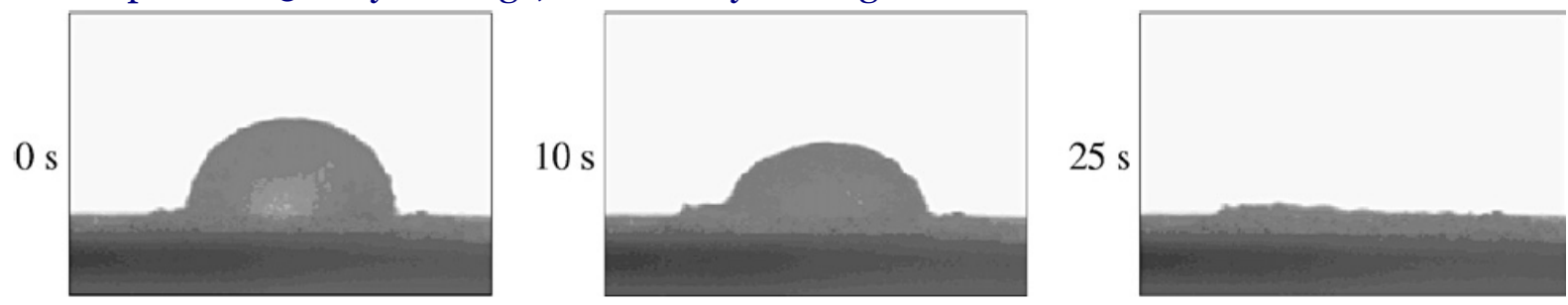

Fig 20: Evolution of the water drop after 36 days storage under constant RH: $33 \%$.

Fig. 21 shows that the water drop still remains on the surface of the powder bed prepared for the sample stored in a desiccator even after 36 days storage.
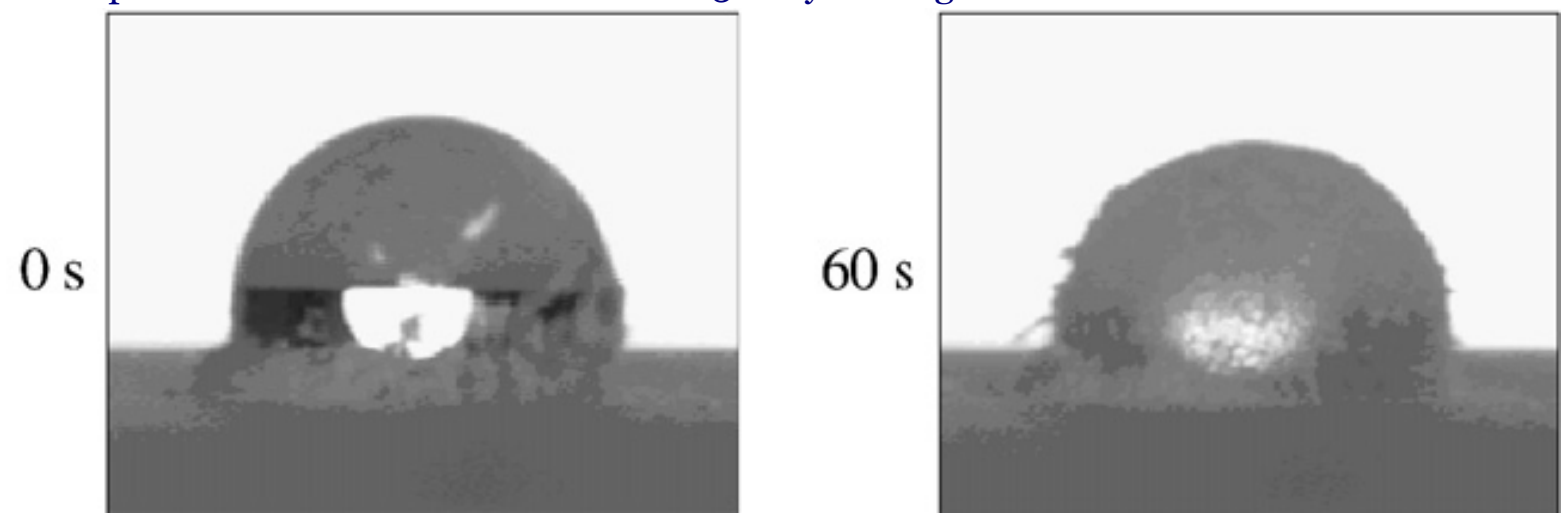

Fig 21: Evolution of the water drop after 36 days storage in a desiccator $(R H<12 \%)$.

The ESEM observations (Fig. 22) show that after 36 days storage the MgSt coverage disappears completely from the surface of the silica gel particles stored $\mathrm{RH}=45 \%$. For the sample stored under constant relative humidity of $33 \%$, the coated surfaces continue to decrease gradually and less coated silica gel particles appear more and more in the sample. The silica gel particles stored at $\mathrm{RH}<12 \%$ are still coated with $\mathrm{MgSt}$ after 36 days storage. 

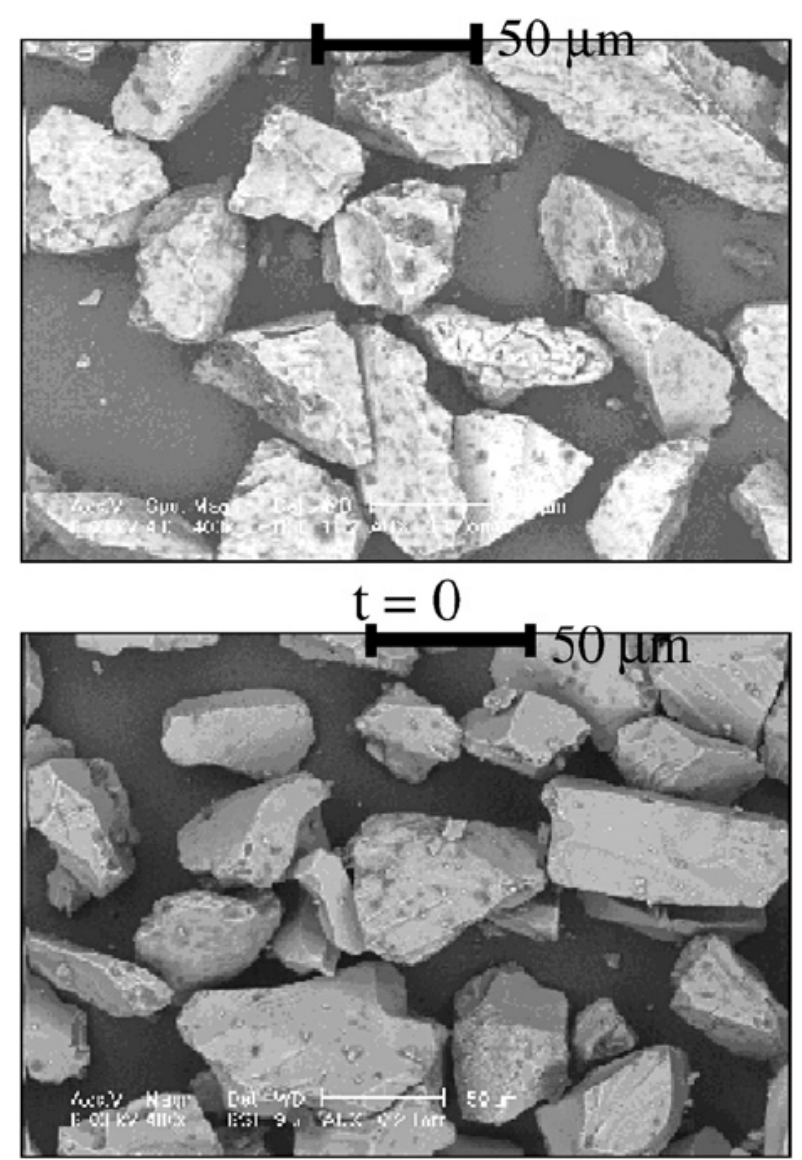

$\mathrm{RH}=33 \%$
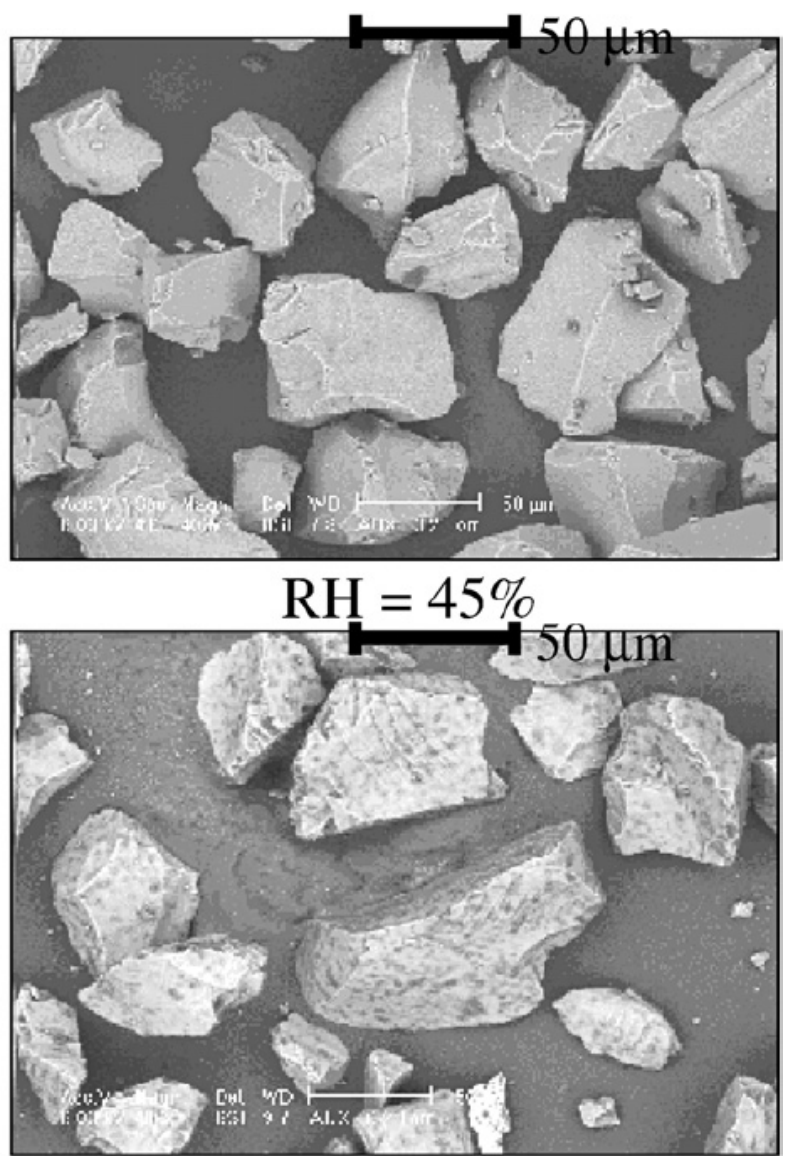

$\mathrm{RH}<12 \%$

Fig 22: ESEM images of silica gel particles coated with 15\% of MgSt at $t=0$ and after 36 days storage under three different relative humidity.

\section{Localisation of the MgSt}

The ESEM images and the variation of the surface property (water drop behaviour) described in the two previous sections reveal an evolution on the MgSt localisation. The magnesium stearate disappeared from the surface. TG-DSC analysis confirms the presence of MgSt in the particles volume (Fig. 23): this presence is characterized by a weight variation around $350{ }^{\circ} \mathrm{C}$. First porosimetry measurements performed with a Micromeritics apparatus and the application of the BJH model showed a reduction of the pore volume of the treated particles after storage under humidity.
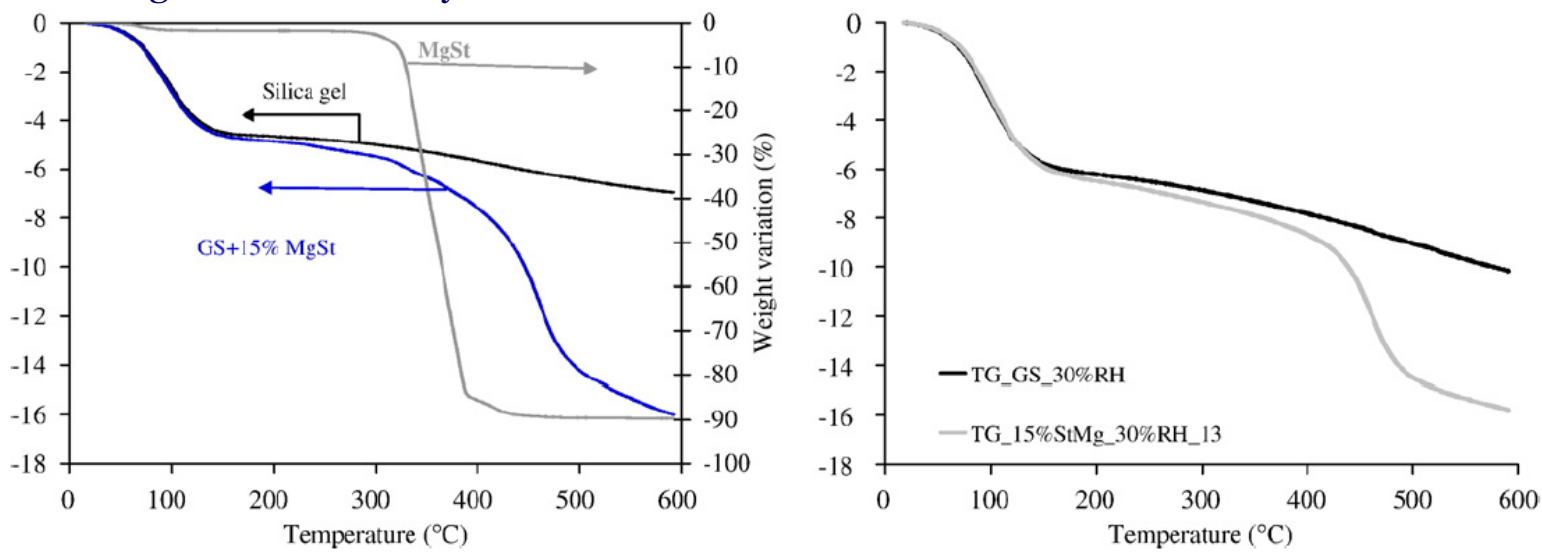

Fig 23: TG-DSC analysis confirms the presence of MgSt after storage under humid atmosphere. 


\section{Conclusion}

This study indicates that it is possible to change the properties of silica gel particles by coating with hydrophobic magnesium stearate using both the Hybridizer and Cyclomix as dry coating devices. The ESEM images of the uncoated and coated particles in the two devices show that MgSt was softened and smeared over host particles. But the silica gel treated alone in the Cyclomix was crushed whereas no difference was observed after processing in the Hybridizer.

The coating of silica gel particles seems to be more uniform and the MgSt is much more softened and smeared over the surface of silica gel particles processed in the Hybridizer than the surface coverage obtained after treatment in the Turbula mixer. The flowability of the silica gel powder was not strongly affected by coating in the Hybridizer and remains good. The flow properties of silica gel are more significantly decreased after treatment in the Turbula mixer than in the Cyclomix mixer. This is probably due to the quality difference in the particle coating. It is also found that the coating by hydrophobic MgSt in both the Hybridizer and Cyclomix can also reduce the high affinity between silica gel and water. The treatment of silica gel powder with $5 \%$ and $15 \%$ of MgSt in the Turbula mixer also reduce its affinity with water.

To summarize, it has been demonstrated that a dry particle coating technique can be used to modify the properties of silica gel powder by coating with small quantities of hydrophobic magnesium stearate in both the Hybridizer and the Cyclomix. The more uniform coating is obtained after treatment in the Hybridizer device.

The study of the ageing of the coated silica gel powder has demonstrated the influence of storage conditions, in particular, the relative humidity on the stability of the coated surfaces. Indeed, for relative humidities varying between $30 \%$ and 50\%, the surface coverage by $\mathrm{MgSt}$ disappears after only 36 days storage. The surface of silica gel particles finds its initial hydrophilic characteristic. Under these conditions of relative humidity, the silica gel powder absorbs water vapour and silanol groups $(\mathrm{Si}-\mathrm{OH})$ are formed onto the surface [21]. On the other hand, the storage under drier air (relative humidity below to $12 \%$ ) preserves the coated surfaces.

Some thermogravimetric analyses evidence that the MgSt material is still in the silica gel particles. To explain the disappearance of MgSt from the surface of silica gel, the mechanism of diffusion of magnesium stearate from the surface into the pores of silica gel particles may be considered. This ageing mechanism is enhanced by high relative humidity. Finely, it is important to confirm by other analysis techniques the validity of this hypothesis of diffusion and what are the major mechanisms to explain the rapid ageing of the coated silica gel powder under humid atmospheres.

\section{References}

[1] I. Yoshihara, W. Pieper, Hybridization - technology for surface modification of powders without binders, Swiss Pharma 6 (1999) 21.

[2] R. Pfeffer, R.N. Dave, W. Dongguang, M. Ramlakhan, Synthesis of engineered particulates with tailored properties using dry particle coating, Powder Technology 117 (2001) 40-67.

[3] S. Kangwantrakool, K. Shinohara, Preparation of newWC-Co/TiC- $\mathrm{AL}_{2} \mathrm{O}_{3}$ composite materials with mechanically coated particles, Journal of Chemical Engineering of Japan 34 (2001) 1486-1492.

[4] J.A. Hersey, Ordered mixing: a new concept in powder mixing, Powder Technology 11 (1975) 41-44. 
[5] J.A. Hersey, Preparation properties ordered mixtures, Aust. Journal of Pharmaceutical Sciences 6 (1977) 29-31.

[6] C.C. Yeung, J.A. Hersey, Ordered powder mixing course fine particulate systems, Powder Technology 22 (1979) 127-131.

[7] C.W. Yip, J.A. Hersey, Segregation ordered powder mixtures, Powder Technology 16 (1977) 149-150.

[8] C.W. Yip, J.A. Hersey, Perfect powder mixtures, Powder Technology 16 (1977) 189-192.

[9] C.W. Yip, J.A. Hersey, Ordered random mixing choice system mixer, Drug Development and Industrial Pharmacy 3 (1977) 429-438.

[10] H. Honda, K. Ono, T. Ishizaka, T. Matsuno, M. Katano, Surface modification of powders by the high speed impact treatment method, Journal of the Society of Powder Technology Japan 24 (1987) 593-599.

[11] H. Honda, T. Matsuno, M. Koishi, Preparation of a graphite fluoride modified polymer microsphere by a high speed impact treatment method, Journal of the Society of Powder Technology Japan 25 (1988) 597-602.

[12] H. Honda, T. Matsuno, M. Koishi, The effect of powder properties on dry impact blending preparation method, Journal of the Society of Powder Technology Japan 25 (1989) 666-671.

[13] H. Honda, M. Kimura, F. Honda, T. Matsuno, M. Koishi, Preparation of composite and encapsulated powder particles by dry impact blending, International Journal of Chemistry and Biotechnology 9 (21) (1991).

[14] A. Mujumdar, D. Wei, R.N. Dave, R. Pfeffer, C.Y. Wu, Improvement of humidity resistance of magnesium powder using dry particle coating, Powder Technology 140 (2004) 86-97.

[15] J. Yang, A. Sliva, A. Banerjee, R.N. Dave, R. Pfeffer, Dry particle coating for improving the of flowability of cohesive powders, Powder Technology 158 (2005) 21-33.

[16] W. Pieper, The Nara hybridization design our own particle, Powder Handling and Processing 8 (1996) 232-234.

[17] B.H. Ng, C.C. Kwan, Y.L. Ding, M. Ghadiri, X.F. Fan, Solids motion in a conical frustumshaped high shear mixer granulator, Chemical Engineering Science 62 (2007) 756-765.

[18] C.C. Kwan, B.H. Ng, Y.L. Ding, R.A. Williams, M. Ghadiri, X.F. Fan, D.J. Parker, Effect of macroscopic flow field on the evolved structure and properties of granules during scaling-up of high shear granulators, 8th International Symposium on agglomeration, Thailand, (2005).

[19] M. Lazghab, S. Khashayar, I. Perzron, P. Guigon, L. Komunjer, Wettability assessment of finely divided solids, Powder Technology 157 (2005) 79-91.

[20] C. Goalard, L. Galet, J.A. Dodds, Characterization of the dispersion behavior of talc, 8th International Symposium on Agglomeration, Proceedings ed N. Sinchaipanid \& al. pp. 121-128, ISBN 974-9717-76-7, Characterisation and Measurement Techniques, Bangkok, Thailand, March 16-18 (2005).

[21] L.T. Zhuravlev, The surface chemistry of amorphous silica. Zhuravlev model, Colloids and Surfaces A: Physicochemical and Engineering Aspects 173 (2000) 1-38. 